\title{
Photolysis of 5-Azido-3-Phenylisoxazole at Cryogenic Temperature: Formation and Direct Detection of a Nitrosoalkene
}

\author{
Upasana Banerjee $^{1}{ }^{(\mathbb{D}}$, William L. Karney ${ }^{2}$, Bruce S. Ault ${ }^{1}$ and Anna D. Gudmundsdottir ${ }^{1, *(D)}$ \\ 1 Department of Chemistry, University of Cincinnati, PO Box 210172, Cincinnati, OH 45221-0172, USA; \\ upasanabanerjee05@gmail.com (U.B.); bruce.ault@uc.edu (B.S.A.) \\ 2 Department of Chemistry, University of San Francisco, 2130 Fulton Street, San Francisco, CA 94117, USA; \\ karney@usfca.edu \\ * Correspondence: anna.gudmundsdottir@uc.edu
}

Received: 23 December 2019; Accepted: 24 January 2020; Published: 27 January 2020

\begin{abstract}
To enhance the versatility of organic azides in organic synthesis, a better understanding of their photochemistry is required. Herein, the photoreactivity of azidoisoxazole $\mathbf{1}$ was characterized in cryogenic matrices with IR and UV-Vis absorption spectroscopy. The irradiation $(\lambda=254 \mathrm{~nm})$ of azidoisoxazole 1 in an argon matrix at $13 \mathrm{~K}$ and in glassy 2-methyltetrahydrofuran (mTHF) at $77 \mathrm{~K}$ yielded nitrosoalkene 3. Density functional theory (DFT) and complete active space self-consistent field (CASSCF) calculations were used to aid the characterization of nitrosoalkene 3 and to support the proposed mechanism for its formation. It is likely that nitrosoalkene 3 is formed from the singlet excited state of azidoisoxazole 1 via a concerted mechanism or from cleavage of an intermediate singlet nitrene that does not undergo efficient intersystem crossing to its triplet configuration.
\end{abstract}

Keywords: photoreactivity; azidoisoxazole; cryogenic matrices; nitrosoalkene; nitrenes

\section{Introduction}

Organic azides are one of the most versatile functional groups in synthesis, as they can be used to form new $\mathrm{C}-\mathrm{N}$ bonds, either through electrophilic or nucleophilic substitution [1]. Additionally, their dipolar character makes them useful for forming new $\mathrm{C}-\mathrm{N}$ bonds through cycloaddition. For example, the Huisgen 1,3-dipolar cycloaddition of organic azides to alkynes is commonly used to form triazole compounds, which have utility in medicinal and pharmaceutical chemistry [2-4]. The pursuit of sustainable chemistry has redirected efforts toward the use of photochemistry for synthetic applications because sunlight, photocatalysts, or eco-friendly light-emitting diodes (LEDs) can be used to drive photoreactions [5]. However, unlike the ground state reactivity of organic azides, their photochemistry is complex and not well understood because the reactivity is affected by both their structure and the environment. Better insight into the photoreaction mechanisms of organic azides will undoubtedly aid in their use in synthetic applications [6].

The photochemistry of vinyl azide derivatives has been studied and their reactivity has been exploited to synthesize various heterocyclic products $[7,8]$. However, for azidoisoxazole derivatives, another type of organic azide, the thermal decomposition behavior has been studied but the photochemistry has not been reported extensively. Kumar et al. and later L'Abbé and Godts studied the thermal decomposition of 4-azidoisoxazole derivatives and demonstrated that they undergo facile cleavage to form cyano products, as shown in Scheme $1[9,10]$, presumably through a concerted reaction mechanism. In comparison, the thermal activation of 3-azidoisoxazole derivatives results in the formation of both isoxazoloisoxazole and hydroxypyrrole products (Scheme 2) [11,12]. L'Abbé and co-workers proposed that these products are formed by different reaction mechanisms, with the 
hydroxypyrroles formed through nitrosoalkene intermediates and the isoxazoloisoxazoles obtained from nitrene intermediates [12].

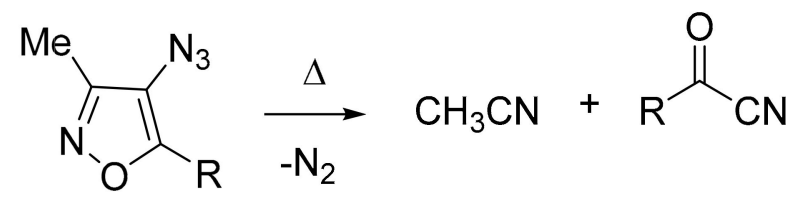

$\mathrm{R}: \mathrm{PhCH}=\mathrm{CH}-$

R: $\mathrm{PhCH}=\mathrm{CH}=\mathrm{CH}$

Scheme 1. Thermal decomposition of 4-azidoisoxazole derivatives.

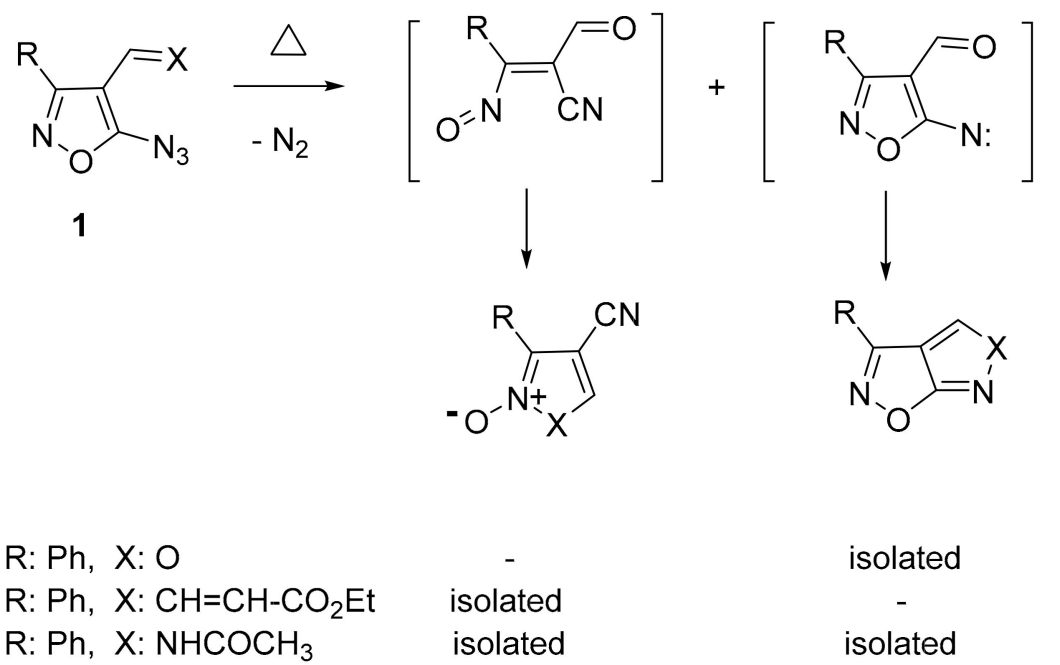

Scheme 2. Thermal activation of 3-azidoisoxazole derivatives.

The thermal decomposition of a 5-azidoisoxazole in the presence of 2,3-dimethyl buta-1,3-diene yields the corresponding oxazine derivative (Scheme 3) [12]. Therefore, it was concluded that the thermal activation of 5-azidoisoxazole yields the corresponding nitrosoalkene, which can be trapped with dienes.

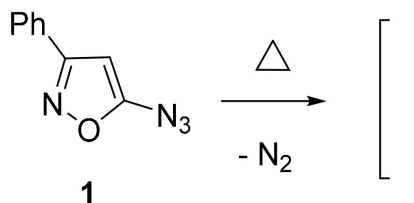<smiles>N#C/C=C(/N=O)c1ccccc1</smiles><smiles>C=C(C)C(=C)C</smiles>

Scheme 3. Trapping of the thermolysis product from azidoisoxazole 1.

In this paper, we report the photoreactivity of azidoisoxazole $\mathbf{1}$ in cryogenic argon and 2-methyltetrahydrofuran (mTHF) matrices. We used IR and UV-Vis absorption spectroscopy to verify that azidoisoxazole $\mathbf{1}$ forms nitrosoalkene 3 . The proposed mechanism for the formation of nitrosoalkene 3 was supported by density functional theory (DFT) and complete active space self-consistent field (CASSCF) calculations.

\section{Results}

\subsection{Matrix IR Spectroscopy}

To determine the photoreactivity of azidoisoxazole $\mathbf{1}$ at cryogenic temperatures, it was deposited into an argon matrix at $13 \mathrm{~K}$ and irradiated with a $254 \mathrm{~nm} \mathrm{UV}$ pen. The reactivity was monitored by IR 
spectroscopy as a function of irradiation time. After $536 \mathrm{~s}$ irradiation, the bands due to azidoisoxazole 1 at $2144,2115,1611,1608,1598,1581,1577,1448,1415,1404,1314,1240,1127,1031,948,915,757$, and 746 $\mathrm{cm}^{-1}$ were fully depleted. Concurrently, several new bands were observed at 2218, 1624, 1573, 1527, $1487,1450,964,829,764,753,696$, and $668 \mathrm{~cm}^{-1}$ (Figure 1a). The intensity of the new bands increased with irradiation time, and they formed at same rate as the bands due to azidoisoxazole 1 were depleted. We assign these new IR bands to nitrosoalkene 3 based on comparison to its calculated IR spectrum. The calculated and scaled (0.9613 [13]) IR spectrum of nitrosoalkene 3 has the most significant bands at 2218 (C $\equiv$ N stretch), 1605, 1559, 1518, 1478, 1427, 955, 827, 754, 750, 680, and $667 \mathrm{~cm}^{-1}$ (Figure 1b,c), which fits with the observed spectrum. It should be noted that the band at $829 \mathrm{~cm}^{-1}$ was considerably weaker than the other experimental bands, and thus, it is only tentatively assigned to nitrosoalkene 3.

In contrast, the computed IR spectrum of singlet nitrene ${ }^{1} \mathbf{2}$ does not fit the experimental IR spectra because the major calculated bands at 1462, 1441, 1409, 1157, 918, 762, 750, 703, and $633 \mathrm{~cm}^{-1}$ (Figure 1b) could not be reasonably matched with the observed major bands. Similarly, the calculated IR spectrum of triplet nitrene ${ }^{3} \mathbf{2}$ does not fit well with the experimental spectra, as the major bands at 1495,1442 , $1435,1386,1170,1157,1147,1075,946,919,730,707,674,670$, and $630 \mathrm{~cm}^{-1}$ (Figure 1b) could not be easily match with the observed major bands. Thus, we conclude that the irradiation of azidoisoxazole $\mathbf{1}$ in argon matrices yields nitrosoalkene 3.

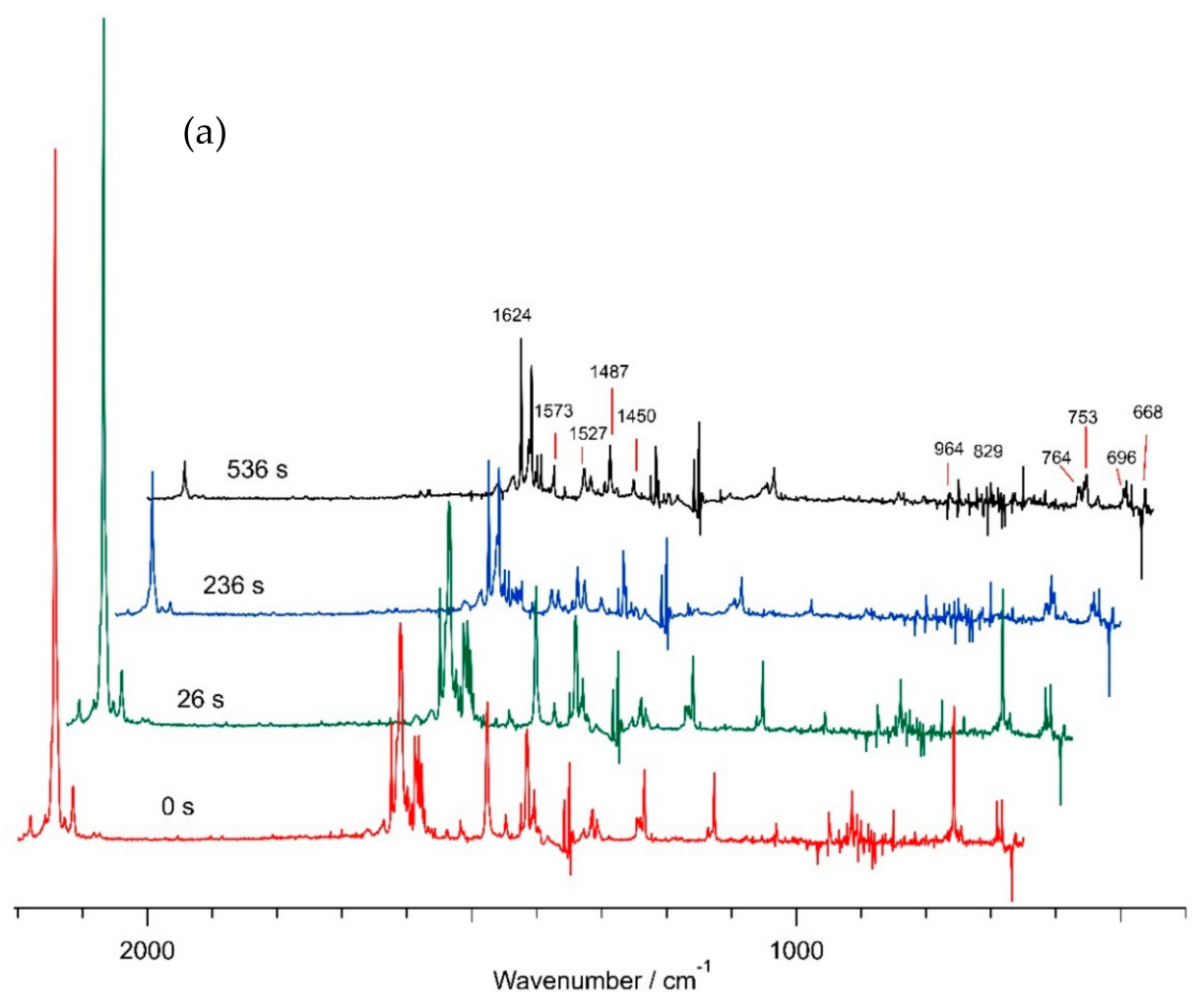

Figure 1. Cont. 

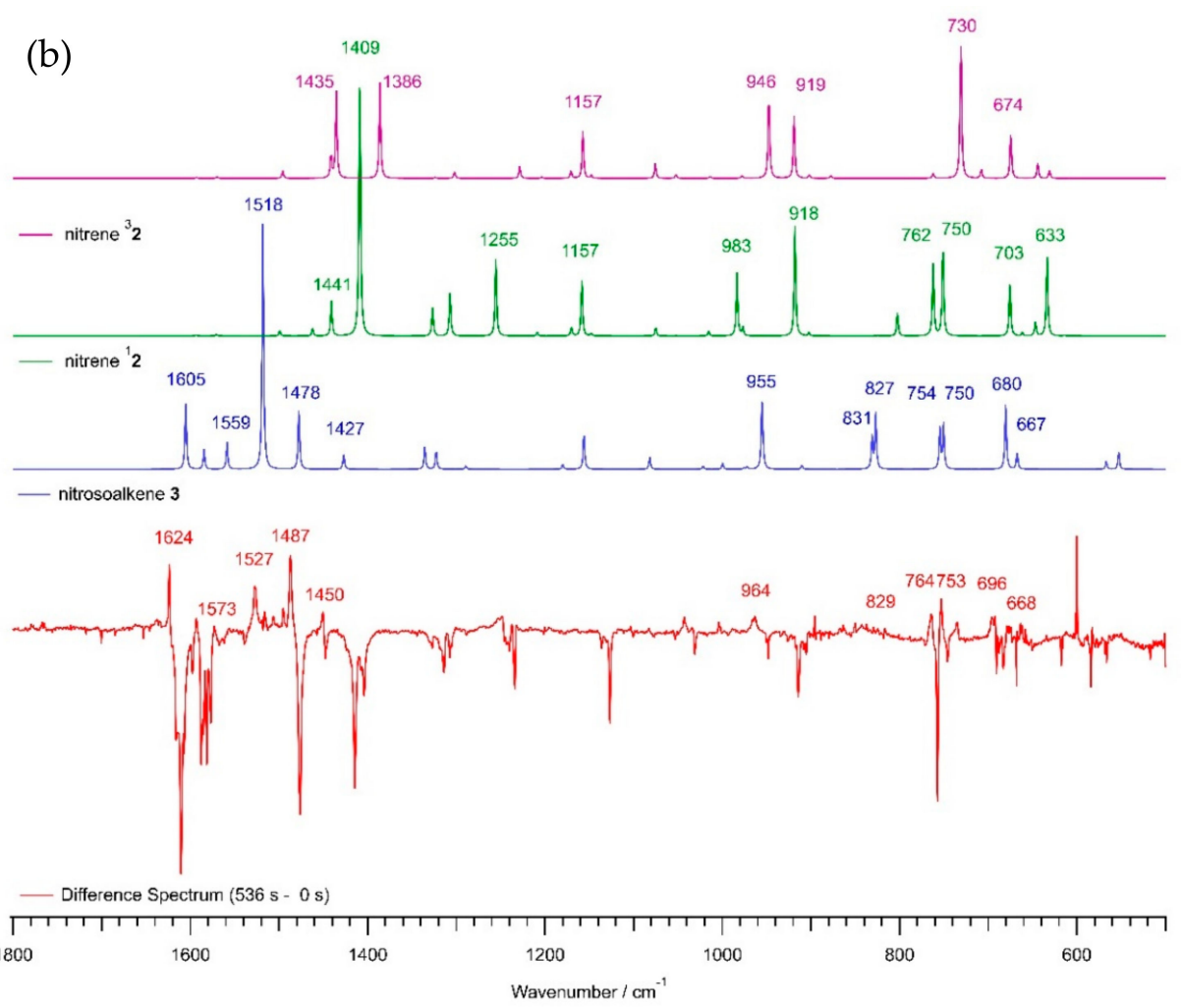

(c)

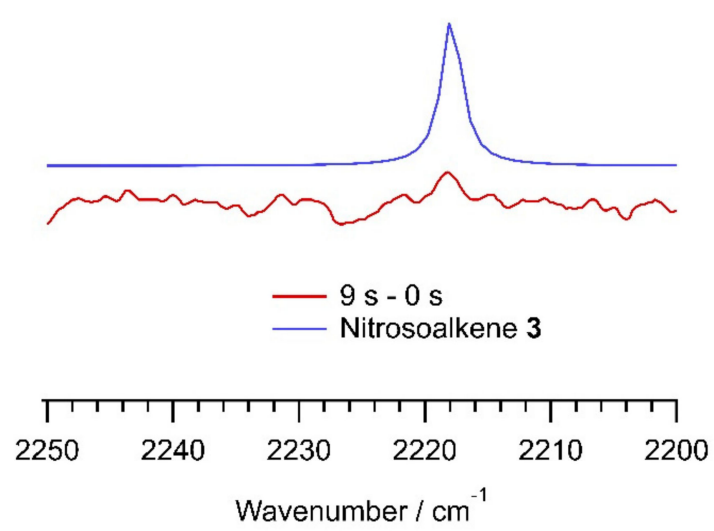

Figure 1. (a) Experimental IR spectra as a function of irradiation time $(\lambda=254 \mathrm{~nm})$ of azidoisoxazole $\mathbf{1}$ in an argon matrix; (b) IR spectra of nitrenes ${ }^{3} \mathbf{2}$ and ${ }^{1} \mathbf{2}$ and nitrosoalkene $\mathbf{3}$ calculated using B3LYP/6-31+G(d) [14] theory and matrix IR difference spectrum (536-0 s); (c) Comparison of matrix IR difference spectrum (536-0 s) with calculated scaled IR spectrum of nitrosoalkene 3.

\subsection{Glassy Matrix UV-Vis Absorption Spectroscopy}

To further characterize nitrosoalkene 3 , its UV-Vis absorption was investigated in a glassy mTHF matrix at $77 \mathrm{~K}$. The absorption spectrum of azidoisoxazole $\mathbf{1}$ in the glassy mTHF matrix was recorded. Then, the matrix was irradiated with a $254 \mathrm{~nm}$ UV pen and the absorption difference spectra were obtained at periodic irradiation times (Figure 2a). Upon irradiation, negative absorption was observed below $300 \mathrm{~nm}$ due to the depletion of azidoisoxazole 1, along with a new broad absorption band with $\lambda_{\max }$ at $\sim 360 \mathrm{~nm}$ and a tail extending to $470 \mathrm{~nm}$. 
(a)

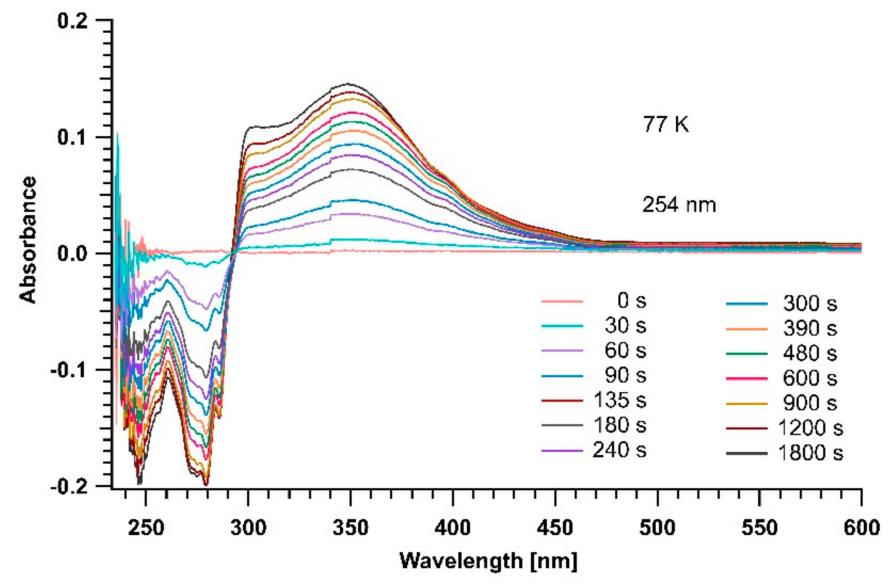

(b)

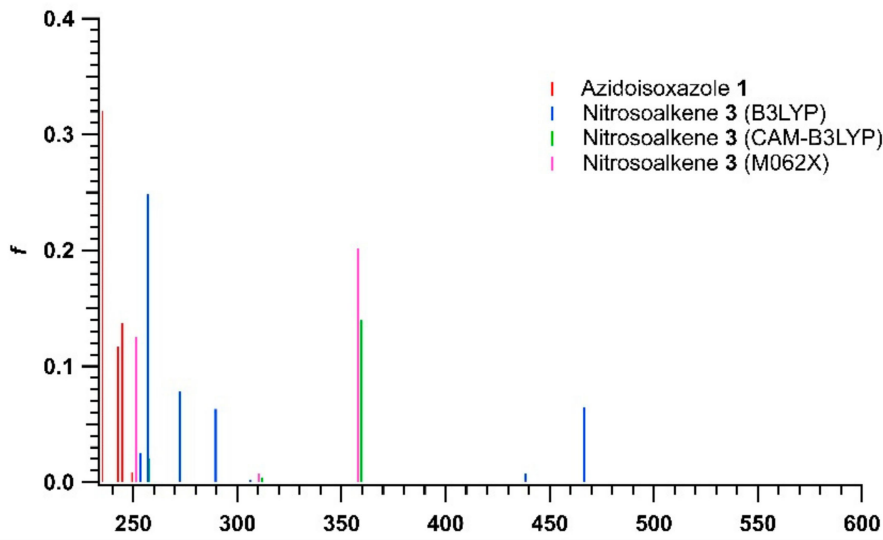

(c)

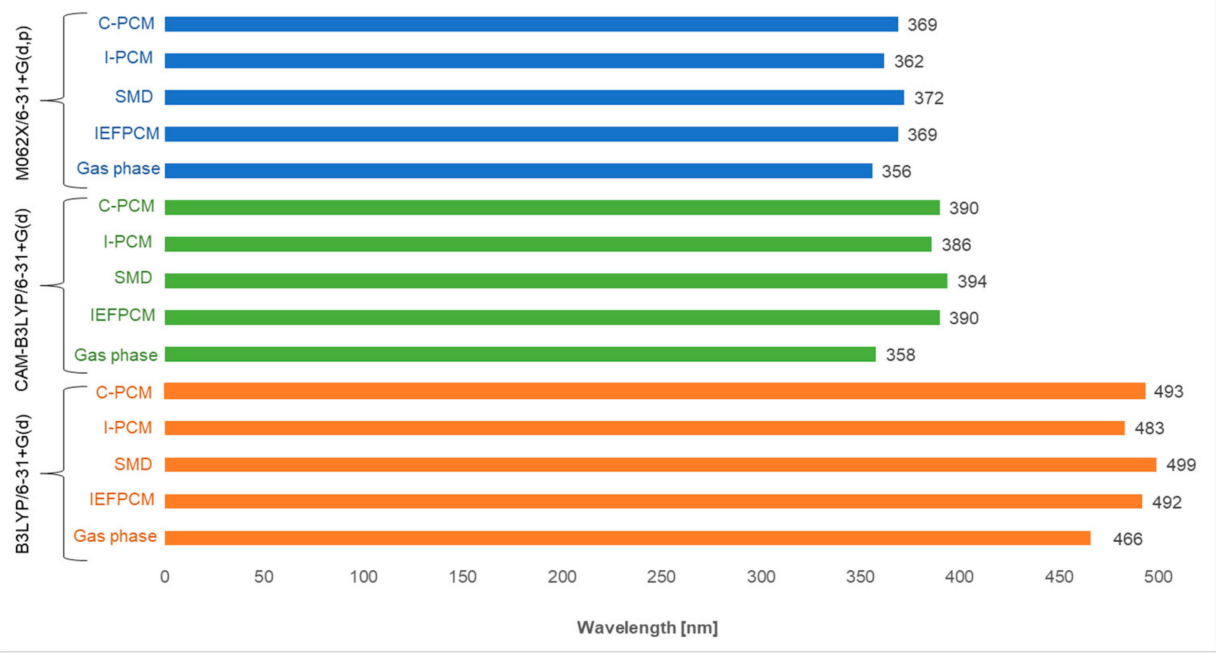

Figure 2. (a) Differential UV-Vis absorption spectra as a function of irradiation time $(\lambda=254 \mathrm{~nm})$ of azidoisoxazole 1 in glassy 2-methyltetrahydrofuran (mTHF) at $77 \mathrm{~K}$; (b) Calculated time-dependent density function theory (TD-DFT) absorption spectra of nitrosoalkene 3 using B3LYP/6-31+G(d), CAM-B3LYP/6-31+G(d), and M06-2X/6-31+G(d,p) using tetrahydrofuran (THF) as an implicit solvent with C-PCM and I-PCM solvation models; (c) Calculated TD-DFT absorption maxima of nitrosoalkene 3 above $300 \mathrm{~nm}$ using B3LYP/6-31+G(d), CAM-B3LYP/6-31+G(d), and M062X/6-31+G(d,p) in the gas phase and using THF as an implicit solvent with C-PCM, I-PCM, SMD, and IEFPCM solvation models.

Time-dependent density function theory (TD-DFT) calculations of the absorption spectrum of nitrosoalkene 3 using the B3LYP/6-31+G(d) level of theory and basis set in the gas phase gave major electron transitions at $257(f=0.2486), 272(f=0.0781), 290(f=0.0632), 438(f=0.0077)$, 
and $466(f=0.0647) \mathrm{nm}$. The calculated bands above $300 \mathrm{~nm}$ overestimate the near-UV absorption band of nitrosoalkene 3 by $\sim 100 \mathrm{~nm}$. The major calculated band at $466 \mathrm{~nm}$ is due to a mixed electronic transition of the lone pair on the oxygen and the aromatic $\pi$-system into an antibonding $\pi$-orbital. In an attempt to obtain a better fit between this band and the observed absorption spectra, we preformed solvation calculations. TD-DFT calculations with tetrahydrofuran (THF) as an implicit solvent and employing several solvation models, such as Integral Equation Formalism version of the Polarizable Continuum Model (IEFPCM) [15], Universal Solvation Model based on Solute Electron Density (SMD) [16], Isodensity Polarizable Continuum Model (I-PCM) [17], and Conductor-like Polarizable Continuum Model (C-PCM) [18], located the major electric transition above $300 \mathrm{~nm}$ at 492 $(f=0.0818), 499(f=0.0834), 483(f=0.0666)$, and $493(f=0.0846) n m$, respectively (Figure 2c). However, these calculations also overestimated the absorption of nitrosoalkene 3 (Figure 2a). Cramer and Truhlar have explained that dispersion forces are important in estimating short-range dielectric polarization effects in the solvation model of an electronic spectrum [19]. Furthermore, the B3LYP level of theory has significant deficiencies when estimating weak but important noncovalent interactions such as van der Waals forces [20,21].

To better model the absorption of nitrosoalkene 3, we optimized its structure using the CAMB3LYP [22] level of theory, which has several long-range corrected functionals, with the 6-31+G(d) basis set. The TD-DFT calculations of nitrosoalkene 3 , in the gas phase and with THF as an implicit solvent, employing IEFPCM [15], SMD [16], I-PCM [17], and C-PCM [18] solvation models, resulted in the major electronic transition above $300 \mathrm{~nm}$ being located at $358(f=0.2017), 390(f=0.1463), 394(f=$ $0.1484), 386(f=0.1197)$, and $390(f=0.1508) \mathrm{nm}$. Although most of these calculations also overestimated the most significant electronic transition for nitrosoalkene 3, in comparison to the observed spectra, they yielded significantly better results than those obtained using the B3LYP level of theory (Figure 2b).

Finally, we opted to use the hybrid functional from Zhao and Truhlar [23] and the M062X level of theory with the $6-31+\mathrm{G}(\mathrm{d}, \mathrm{p})$ basis set to optimize nitrosoalkene 3 and calculate its absorption spectrum, as these hybrid functionals have shown promising results in predicting dispersion forces. The TD-DFT/M062X calculated spectrum of nitrosoalkene 3 in the gas phase and with THF as an implicit solvent with IEFPCM, SMD, I-PCM, and C-PCM solvation models exhibited major transitions above $300 \mathrm{~nm}$ at $356(f=0.2017), 369(f=0.1463), 372(f=0.1484), 362(f=0.1197)$, and $369(f=0.1508) \mathrm{nm}$, which match well with the observed spectrum of nitrosoalkene 3 . Thus, we conclude that irradiation of azidoisoxazole $\mathbf{1}$ in mTHF matrices results in the formation of nitrosoalkene $\mathbf{3}$, as observed upon irradiation in argon matrices.

Based on the fact that photolysis of azidoisoxazole $\mathbf{1}$ in cryogenic matrices results in the formation of nitrosoalkene 3 and because we did not observe the formation of either singlet or triplet nitrene 2, we theorize that azidoisoxazole 1 forms nitrosoalkene 3 in a concerted manner from the singlet excited state $\left(S_{1}\right)$ of azidoisoxazole 1 (pathway 1 , Scheme 4 ). However, it is possible that the $S_{1}$ of azidoisoxazole 1 forms singlet lnitrene ${ }^{1} \mathbf{2}$, which subsequently rearranges into nitrosoalkene 3 (pathway 2, Scheme 4). Furthermore, if nitrene ${ }^{1} \mathbf{2}$ is formed, we cannot rule out that it intersystem crosses to its triplet configuration, nitrene ${ }^{3} 2$, which could then rearrange and intersystem cross to form nitrosoalkene 3 (pathway 3, Scheme 4). 


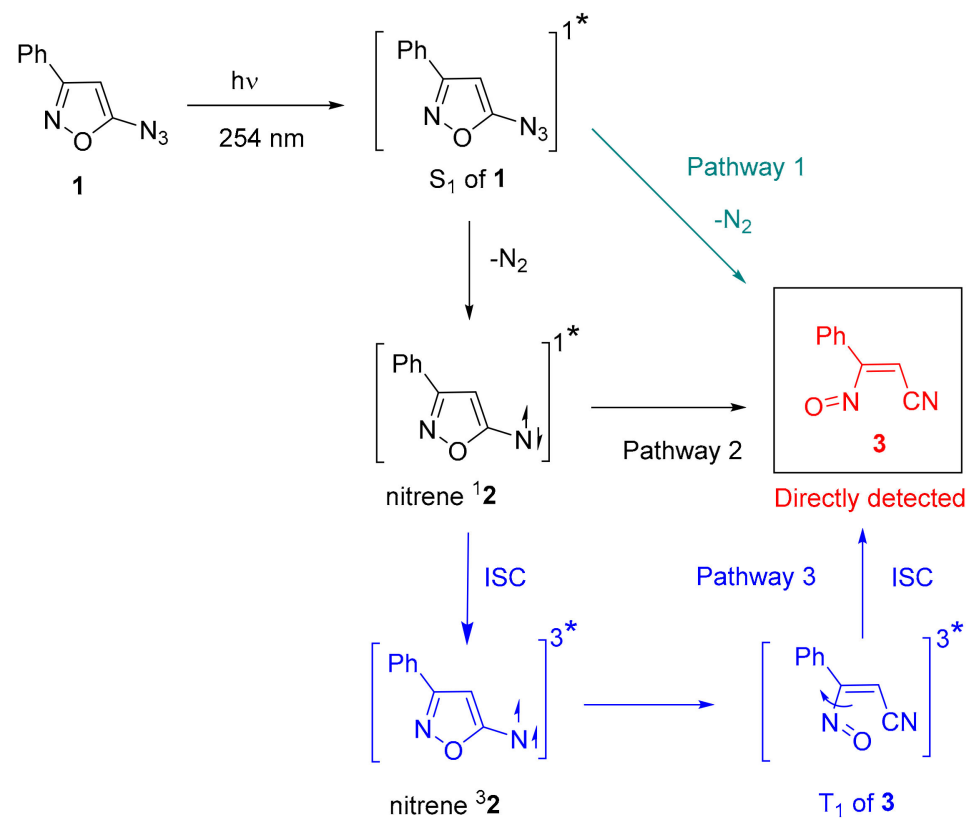

Scheme 4. Photoreactivity of azidoisoxazole 1 in cryogenic matrices.

\subsection{Quantum Chemical Calculations}

To determine the feasibility of the various pathways displayed in Scheme 4, we calculated the stationary points on the potential energy diagram using DFT calculations (Gaussian 16, B3LYP/6-31+G(d) $[14,24,25])$. We optimized the structure of azidoisoxazole $\mathbf{1}$ and obtained two minimal energy conformations, $\mathbf{A}$ and $\mathbf{B}$, which differed mainly in the orientation of the azido chromophore (Figure 3). The calculated energies of azidoisoxazole $\mathbf{1 A}$ and $\mathbf{1 B}$ were within $1 \mathrm{kcal} / \mathrm{mol}$ of each other, with A being the more stable conformation. TD-DFT calculations were performed to locate the vertical excitation energies of the first singlet and triplet excited states $\left(\mathrm{S}_{1}\right.$ and $\left.\mathrm{T}_{1}\right)$ of azidoisoxazole 1. The $S_{1}$ of $\mathbf{1}$ and the $T_{1}$ of $\mathbf{1}$ were located 86 and $64 \mathrm{kcal} / \mathrm{mol}$, respectively, above the ground state $\left(\mathrm{S}_{0}\right)$. The open shell triplet and singlet configurations of nitrene 2 were optimized, with the singlet configuration being optimized using a broken symmetry calculation, as achieved using guess $=\mathrm{mix}$ as a keyword in Gaussian 16 (Figure 3). Triplet nitrene 2 was $11 \mathrm{kcal} / \mathrm{mol} \mathrm{more} \mathrm{stable} \mathrm{than} \mathrm{the} \mathrm{singlet}$ configuration; however, it should be noted that due to spin contamination, DFT calculations do not accurately estimate the energy gap between singlet and triplet nitrenes. Furthermore, we optimized two minimal conformers of nitrosoalkene, $\mathbf{3 A}$ and $\mathbf{3 B}$, with $\mathbf{3 A}$ being $2 \mathrm{kcal} / \mathrm{more}$ stable than $\mathbf{3 B}$ (Figure 3).

Due to the high spin contamination in the DFT calculations, the singlet and triplet configurations of nitrene 2 were also computed using the CASSCF and CASPT2 methods (Table 1). At the CASPT2(14,13)/cc-pVTZ//CASSCF(14,13)/cc-pVDZ level of theory, ${ }^{1} \mathbf{2}$ is predicted to lie $13.8 \mathrm{kcal} / \mathrm{mol}$ above $^{3} 2$. 


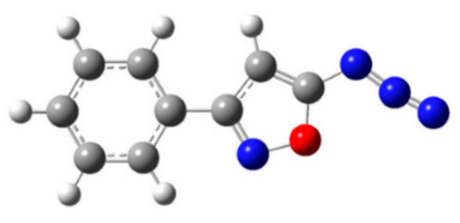

Azidoisoxazole 1A (0)

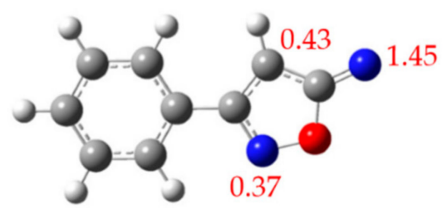

Nitrene ${ }^{32}(1)$

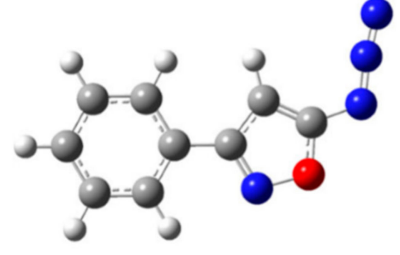

Azidoisoxazole 1B (1)

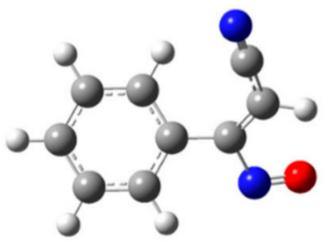

Nitrosoalkene 3A $(-12)$

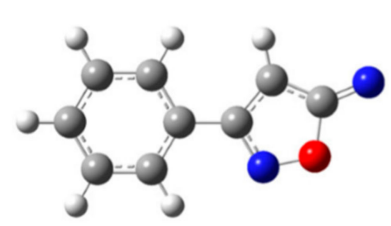

Nitrene ${ }^{1} 2(12)$

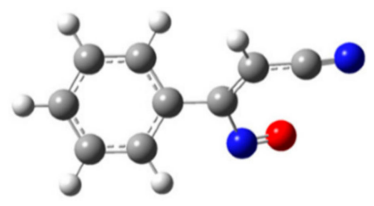

Nitrosoalkene 3B (-10)

Figure 3. Optimized structures of azidoisoxazole $\mathbf{1}$, nitrene ${ }^{1} \mathbf{2}$, nitrene ${ }^{3} \mathbf{2}$, and nitrosoalkene $\mathbf{3}$ using the B3LYP/6-31+G(d) level of theory. The numbers in parentheses are the energies in $\mathrm{kcal} / \mathrm{mol}$ relative to the energy of conformer A of $\mathbf{1}$. The calculated spin densities of nitrene ${ }^{3} \mathbf{2}$ are displayed in red.

Table 1. Computed singlet-triplet energy gaps (kcal/mol) for Nitrene 2.

\begin{tabular}{cc}
\hline Method & Singlet Energy \\
\hline CASSCF(14,13)/cc-pVDZ & 13.9 \\
CASPT2(14,13)/cc-pVDZ & 15.2 \\
CASPT2(14,13)/ANO-S & 14.3 \\
CASPT2(14,13)/cc-pVTZ & 13.8 \\
\hline
\end{tabular}

Energy of ${ }^{1} \mathrm{~A}^{\prime \prime}$ singlet state relative to ${ }^{3} \mathrm{~A}^{\prime \prime}$ triplet state. All energies were obtained at the CASSCF(14,13)/cc-pVDZ geometries and are corrected for differences in zero-point energies.

Finally, we calculated stationary points on the singlet and triplet excited state surfaces of azidoisoxazole 1 for the formation of nitrosoalkene 3 . However, due to spin contamination, we could not use DFT to optimize the transition state of $S_{1}$ of $\mathbf{1}$ for the formation of nitrene ${ }^{1} \mathbf{2}$ or that of nitrene ${ }_{1} \mathbf{2}$ for the formation of nitrosoalkene $\mathbf{3}$. In contrast, we calculated the transition state barrier for nitrene ${ }^{3} \mathbf{2}$ to form nitrosoalkene ${ }^{3} \mathbf{3}$, which is located $10 \mathrm{kcal} / \mathrm{mol}$ above nitrene ${ }^{3} \mathbf{2}$. The calculated stationary points on the energy surface of azidoisoxazole $\mathbf{1}$ are displayed in Figure 4. 


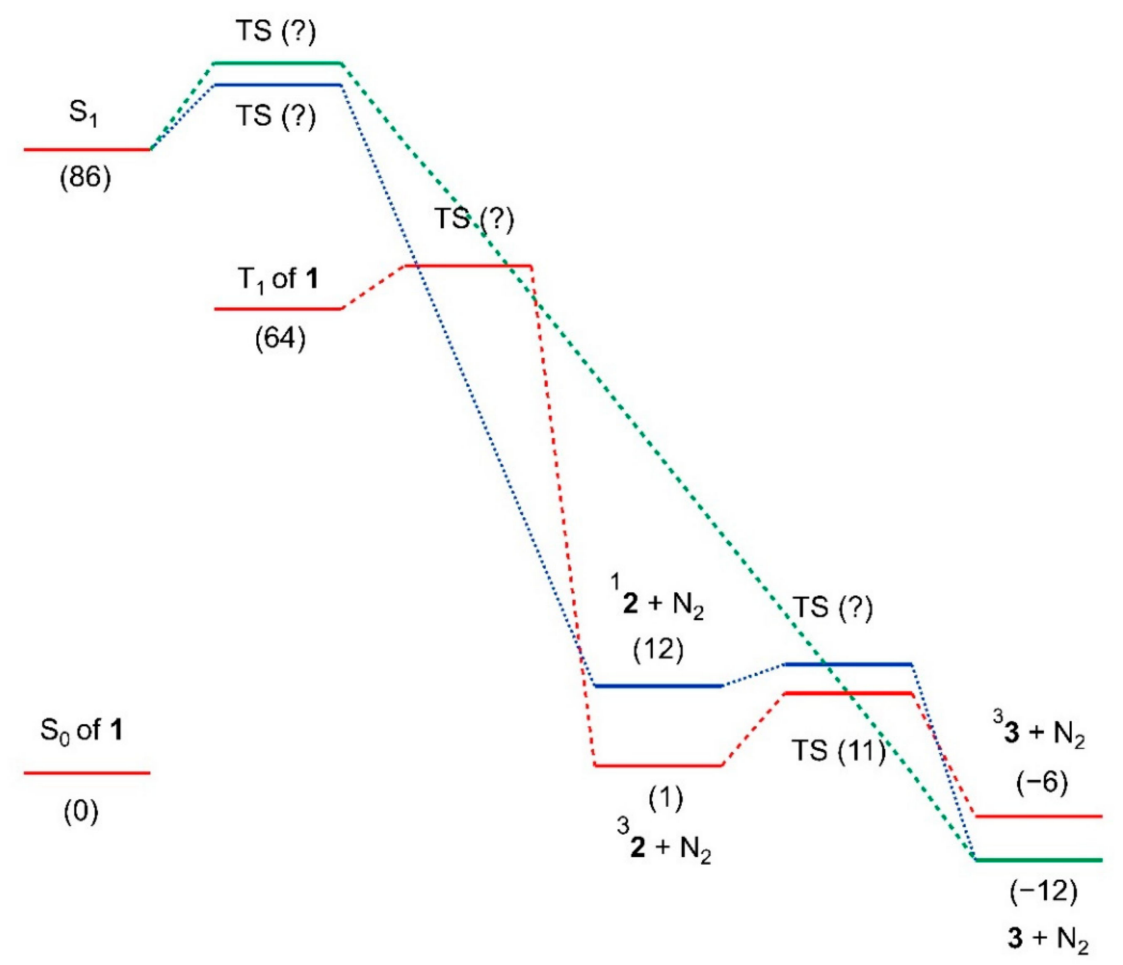

Figure 4. Calculated stationary points on the singlet and triplet energy surfaces of azidoisoxazole 1 using the B3LYP/6-31+G(d) level of theory. The numbers in parentheses are the energies in $\mathrm{kcal} / \mathrm{mol}$.

\section{Discussion}

Because the energy gap between the $S_{1}$ and $T_{1}$ of azidoisoxazole 1 was large ( $\left.22 \mathrm{kcal} / \mathrm{mol}\right)$, intersystem crossing between these excited states was not expected to be efficient. Thus, it is reasonable that the photoreactivity of azidoisoxazole 1 occurred from its singlet excited state. The calculated energy gap between nitrenes ${ }^{1} \mathbf{2}$ and ${ }^{3} \mathbf{2}(13.8 \mathrm{kcal} / \mathrm{mol})$ was slightly less than the singlet-triplet energy gap measured for phenylnitrene $(14.9 \mathrm{kcal} / \mathrm{mol})[26,27]$. At cryogenic temperatures, irradiation of phenyl azide resulted in the formation of triplet phenylnitrene via intersystem crossing from singlet phenylnitrene. Thus, the reactivity of azidoisoxazole $\mathbf{1}$ at cryogenic temperatures was different from that of phenyl azide, as a stable triplet nitrene was not formed [28,29].

Based on computational studies of radical stabilization in furanylnitrenes using the spin-flip coupled-cluster method [30], Wenthold reported that the singlet-triplet energy gap of 2-furanylnitrene is only $10.9 \mathrm{kcal} / \mathrm{mol}$ (Scheme 5). He attributed the decreased singlet-triplet energy gap of 2-furanylnitrene to radical stabilization of its singlet state resulting from increased delocalization and decreased electron pair repulsion. In comparison, the calculated singlet-triplet energy gap of 3-furanylnitrene was larger $(17.3 \mathrm{kcal} / \mathrm{mol})$ due to a decrease in delocalization. 
<smiles>[N]c1ccco1</smiles>

SC-CCSD(T)/cc-pVTZ 10.9<smiles>Nc1ccno1</smiles>

$13.8 \mathrm{kcal} / \mathrm{mol}$<smiles>[N-]=[N+]=[N-]</smiles>

17.3<smiles>N#Cc1ccccc1</smiles>

$15.4 \mathrm{kcal} / \mathrm{mol}$<smiles>N#[N+]c1ccccc1</smiles>

Experimental $14.9 \mathrm{kcal} / \mathrm{mol}$

Scheme 5. Singlet-triplet energy gaps for furanylnitrenes and phenylnitrene.

Additionally, 3-furanylnitrene has been reported to be formed by direct irradiation of 3-furanylisocyanate in cryogenic matrices, presumably because intersystem crossing from the singlet to the triplet nitrene is efficient (Scheme 6) [31]. In contrast, photolysis of 2-furanylisocyanate gives cyanoacrolein rather than 2-furanylnitrene because 2-furanylisocyanate reacted in a concerted manner to form cyanoacrolein or through singlet 2-furanylnitrene, which underwent cleavage faster than it intersystem crossed to its triplet configuration. Thus, the photoreactivity of azidoisoxazole 1 resembled that observed for 2-furanylisocyanate.

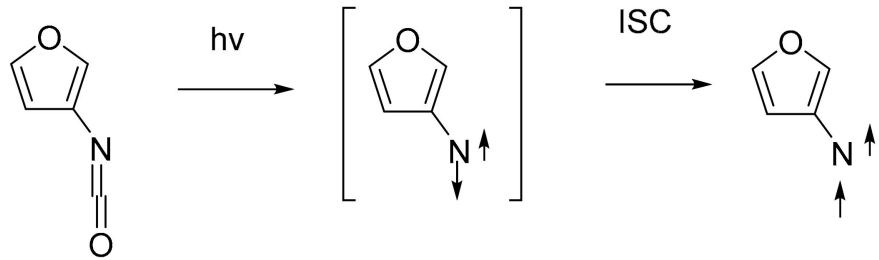

3-furanylisocyanate singlet 3-furanylnitrene triplet 3-furanylnitrene

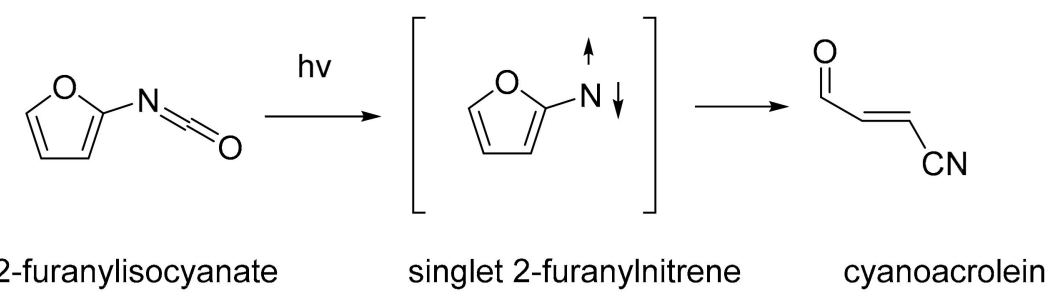

Scheme 6. Photoreactivity of furanylisocyanates in cryogenic matrices.

Finally, the photoreactivity of azidoisoxazole 1 was compared with that of isoxazoles in cryogenic matrices. The irradiation of isoxazole derivatives at cryogenic temperatures resulted in the formation of the corresponding ketenimine. It has been theorized that the ketenimines are formed by intersystem crossing from triplet vinylnitrenes that are not stable (Scheme 7) [32-34]. Triplet vinylnitrenes can, however, be detected directly by laser flash photolysis of their isoxazole precursors in solution at ambient temperature [32,35]. Furthermore, they can be rendered stable at cryogenic temperatures by incorporating the vinyl bond into a cyclic structure (Scheme 8). The CASPT2 calculated singlet-triplet energy gaps of cyclic vinylnitrenes, reported to be between 10 and $13 \mathrm{kcal} / \mathrm{mol}$, were similar to or slightly smaller than those calculated for nitrene $\mathbf{2}$ [36-39]. Thus, azidoisoxazole $\mathbf{1}$ reacts differently from isoxazole derivatives because it does not undergo cleavage of its $\mathrm{C}-\mathrm{O}$ bond, as its azido moiety is more reactive. 


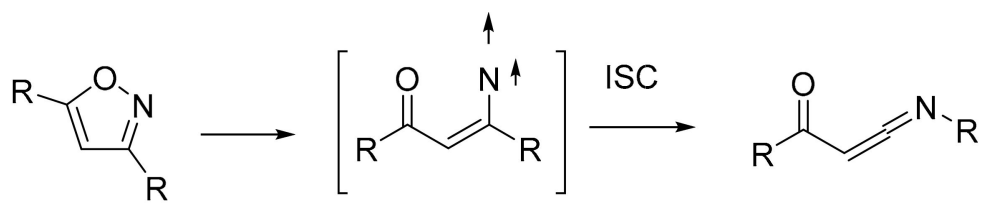

$\mathrm{R}=\mathrm{CH}_{3}$

$\mathrm{R}=\mathrm{H}$

Scheme 7. Photoreactivity of isoxazoles in cryogenic matrices.<smiles>[N-]C1=CC(=O)CC1</smiles>

12.0<smiles>N#CC1=CC(=O)CCC1</smiles>

11.2<smiles>N#CC1=CC(=O)c2ccccc2C1=O</smiles>

13.0<smiles>NC1=CC(=O)c2ccccc21</smiles>

$10.3 \mathrm{kcal} / \mathrm{mol}$

Scheme 8. Calculated singlet-triplet energy gaps of cyclic vinylnitrenes.

Because we did not observe nitrene ${ }^{3} 2$ in cryogenic matrices, not even at shorter irradiation times, it seems likely that the reactivity occurs on the singlet surface of azidoisoxazole 1 in a concerted manner or that nitrene ${ }^{1} \mathbf{2}$ cleaves more efficiently to form nitrosoalkene 3 than it can intersystem cross to nitrene ${ }^{3} 2$.

\section{Materials and Methods}

\subsection{Preparation of Azidoisoxazole 1}

Azidoisoxazole 1 was synthesized by following the previously reported procedure [12]. Sodium hydride $(0.041 \mathrm{~g}, 1.7 \mathrm{mmol})$ was placed a $25 \mathrm{~mL}$ round bottom flask, washed three times with hexane $(2 \mathrm{~mL})$ and once with dichloromethane $(2 \mathrm{~mL})$, and then vacuum dried for $1 \mathrm{~h}$. Dry THF ( $3 \mathrm{~mL})$ was added to the round bottom flask and the reaction was cooled to $-30{ }^{\circ} \mathrm{C}$ using a xylene-dry ice bath. A solution of 5-amino-3-phenyl isoxazole $(0.16 \mathrm{~g}, 0.99 \mathrm{mmol})$ and tosyl azide $(1.5 \mathrm{~mL}, 7.5 \mathrm{mmol})$ in dry THF ( $3 \mathrm{~mL}$ ) was added dropwise to the cooled suspension over $10 \mathrm{~min}$ under an argon atmosphere. The xylene bath temperature was raised to room temperature and the black reaction mixture was stirred overnight, diluted with water $(25 \mathrm{~mL})$, extracted with diethyl ether $(25 \mathrm{~mL})$, and dried under reduced pressure. Azidoisoxazole 1 was purified by silica gel column chromatography eluted with 5\% ethyl acetate in hexane. Recrystallized azidoisoxazole 1 crystals (diethyl ether; $50 \mathrm{mg}$, 17\% yield) were characterized using ${ }^{1} \mathrm{H}-\mathrm{NMR}$ and IR spectroscopy, and the obtained spectra corresponded well with the reported data [12]. ${ }^{1} \mathrm{H}-\mathrm{NMR}\left(400 \mathrm{MHz}_{\mathrm{CDCl}}\right): 7.77-7.74(\mathrm{~m}, 2 \mathrm{H}), 7.48-7.45(\mathrm{~m}, 3 \mathrm{H}), 6.01(\mathrm{~s}, 1 \mathrm{H})$ ppm; IR (neat): 3129, 3059, 2121, 1598, 1570, 1469, 1368, $1168 \mathrm{~cm}^{-1}$.

\subsection{Matrix IR Spectroscopy}

Apparatus description: Matrix isolation of azidoisoxazole $\mathbf{1}$ in argon matrices was performed on conventional equipment [40]. This experiment was conducted in a completely stainless-steel home built vacuum system, with Nupro Teflon-seat valves (Swagelok Company, Colon, Ohio, USA). Pumping was provided by a Model 1402B Welch vacuum pump (Sargent Wlech Corporation, Buffalo Grove, Illinois, USA), and a Varían M-2 diffusion pump (Varian Corporation, Palo Alto, California, USA), with liquid nitrogen trap. Pressures near $10^{-7} \mathrm{~mm}$ at the gauge (cold cathode, Varían) were generally recorded at the start of an experiment. Cryogenics were supplied by a Model 21 closed cycle refrigerator $(\mathrm{CTi}$, Inc., Waltham, Massachusetts, USA), operating down to $13 \mathrm{~K}$. Argon was deposited on a CsI window. The sample was deposited by heating for $3.5 \mathrm{~h}$ at $313 \mathrm{~K}\left(40{ }^{\circ} \mathrm{C}\right)$, followed by $30 \mathrm{~min}$ at $315 \mathrm{~K}\left(42{ }^{\circ} \mathrm{C}\right)$ under vacuum. The vaporized sample was entrained in flowing argon $(2 \mathrm{mmol} / \mathrm{h})$, carried to the cryogenic surface and deposited. 
The matrix was irradiated through a $\mathrm{KBr}$ window with a UV pen $(\lambda=254 \mathrm{~nm})$. IR spectra at $1 \mathrm{~cm}^{-1}$ resolution were collected periodically as a function of irradiation time with a Perkin Elmer 100 Fourier transform infrared spectrometer (Perkin Elmer Corportation, Waltham, Massachusetts, USA). We used IgorPro8 software to plot and process the data.

\subsection{Glassy Matrix UV-Vis Absorption Spectroscopy}

Apparatus description: Glassy matrix UV-Vis spectroscopy was performed using the following instrumentation setup. The cryostat unit is a commercial Optistat DN2, a Variable Temperature Liquid Nitrogen Cryostat obtained from Oxford Instruments, Concord, Massachusetts, USA. (Temperature can be varied between $77 \mathrm{~K}$ and $500 \mathrm{~K}$ ). Mercury iTC cryogenic environment controller was obtained from the same commercial source and it was used as a temperature controller. Vacuum chambers were pumped to high vacuum using KJLC RV series Rotary Vane pump to create thermal isolation. We used JASCO V-750 spectrophotometer (from JASCO Easton, Maryland, USA) for recording UV-Vis spectra. IgorPro8 software was used for plotting and processing the data.

A stock solution of azidoisoxazole $1(1.2 \mathrm{mg}, 0.0001 \mathrm{mmol})$ in $\mathrm{mTHF}(0.5 \mathrm{~mL})$ was prepared. Subsequently, $0.01 \mathrm{~mL}$ of this stock solution was added to $\mathrm{mTHF}(2 \mathrm{~mL})$ and the resulting solution was placed in a quartz cuvette. After degassing the solution by bubbling with argon for 3 min, the cuvette was capped and sealed with Teflon tape. The UV-Vis absorption spectrum of $\mathbf{1}$ at ambient temperature showed a broad absorption band up to $300 \mathrm{~nm}$ (see Figure S1) and the maximum absorbance of the solution was below 0.6 . This solution was cooled to $77 \mathrm{~K}$ using liquid nitrogen to form a glassy $\mathrm{mTHF}$ matrix. The absorption spectrum of $\mathbf{1}$ before irradiation $(0 \mathrm{~min})$ was recorded and then set as the baseline. Then, the glassy mTHF matrix was irradiated with a $254 \mathrm{~nm}$ UV pen and the absorption difference spectrum was collected periodically.

\subsection{Quantum Chemical Calculations}

Geometries of all species were optimized at the B3LYP, CAM-B3LYP, and M06-2X levels of theory with the $6-31+\mathrm{G}(\mathrm{d})$ basis set, as implemented in the Gaussian 16 programs at the Ohio Supercomputer Center [14,23,24,41]. The absorption spectra were calculated using TD-DFT calculations [42,43] in the gas phase and with THF as an implicit solvent employing IEFPCM [15], SMD [16], I-PCM [17], and C-PCM [18] solvation models. The calculated IR spectra of the intermediates and products were obtained by frequency calculations using the parameters mentioned above, and the frequencies were scaled by a factor of 0.9613 [13]. The transition states were confirmed to have one imaginary vibrational frequency by analytical determination of the second derivative of the energy with respect to the internal coordinates. Intrinsic reaction coordinate (IRC) calculations were used to verify that the transition states were correlated with the products and the precursors [44,45].

CASSCF and CASPT2 calculations on nitrene 2 employed a 14-electron, 13-orbital active space consisting of all $\pi / \pi^{*}$ MOs plus the in-plane nonbonding $\mathrm{MO}$ on the nitrene nitrogen. The CASSCF and CASPT2 calculations were performed with Molcas 8.2 [46]. The molecular orbitals (MOs) were visualized with Molden [47].

\section{Conclusions}

IR and UV-Vis absorption spectroscopy verified that irradiation of azidoisoxazole $\mathbf{1}$ in cryogenic matrices results in the formation of nitrosoalkene 3. Thus, both thermal and light activation of azidoisoxazole $\mathbf{1}$ yield the same product. Because the formation of nitrene ${ }^{3} \boldsymbol{2}$ was not observed in cryogenic matrices, it was concluded that nitrosoalkene 3 is formed in a concerted manner from the singlet excited state of azidoisoxazole $\mathbf{1}$ or from nitrene ${ }^{1} \mathbf{2}$, which does not intersystem cross to its triplet configuration as efficiently as it cleaves to form nitrosoalkene $\mathbf{3}$. Thus, azidoisoxazole $\mathbf{1}$ is an efficient precursor of nitrosoalkene 3 . 
Supplementary Materials: The following are available online at http://www.mdpi.com/1420-3049/25/3/543/s1, Figure S1: UV-Vis absorption spectra of azidoisoxazole 1. Optimized structures of 1-3; CASSCF and CASPT2 absolute energies of nitrenes ${ }^{1} \mathbf{2}$ and ${ }^{3} 2$.

Author Contributions: A.D.G. guided the research, and U.B. and B.S.A. performed the experiments. U.B. and W.L.K. carried out the computational study. All authors contributed to writing and proofreading the manuscript and have read and approved the final manuscript.

Funding: This research was funded by the National Science Foundation (NSF) (grant numbers CHE-1800140 and CHE-1565793), and the Ohio Supercomputer Center (OSC) (grant number PES-0597).

Acknowledgments: U.B. is grateful for Ann P. Villalobos/Lange and Laws Fellowships from the UC Chemistry Department.

Conflicts of Interest: The authors declare no conflict of interest.

\section{References}

1. Bräse, S.; Gil, C.; Knepper, K.; Zimmermann, V. Organic azides: An exploding diversity of a unique class of compounds. Angew. Chem. Int. Ed. 2005, 44, 5188-5240. [CrossRef] [PubMed]

2. Kacprzak, K.; Skiera, I.; Piasecka, M.; Paryzek, Z. Alkaloids and isoprenoids modification by copper(I)-catalyzed Huisgen 1,3-dipolar cycloaddition (click chemistry): Toward new functions and molecular architectures. Chem. Rev. 2016, 116, 5689-5743. [CrossRef] [PubMed]

3. Meldal, M.; Tornøe, C.W. Cu-catalyzed azide-alkyne cycloaddition. Chem. Rev. 2008, 108, $2952-3015$. [CrossRef] [PubMed]

4. Mandoli, A. Recent advances in recoverable systems for the copper-catalyzed azide-alkyne cycloaddition reaction (CuAAC). Molecules 2016, 21, 1174. [CrossRef] [PubMed]

5. Schultz, D.M.; Yoon, T.P. Solar synthesis: Prospects in visible light photocatalysis. Science 2014, 343, 1239176. [CrossRef] [PubMed]

6. Banerjee, U.; Thenna-Hewa, K.; Gudmundsdottir, A.D. Triplet vinylnitrenes. In Patai's Chemistry of Functional Group; Rappoport, Z., Ed.; Wiley: Hoboken, NJ, USA, 2019; pp. 1-37.

7. Fu, J.; Zanoni, G.; Anderson, E.A.; Bi, X. $\alpha$-Substituted vinyl azides: An emerging functionalized alkene. Chem. Soc. Rev. 2017, 46, 7208-7228. [CrossRef]

8. Hayashi, H.; Kaga, A.; Chiba, S. Application of vinyl azides in chemical synthesis: A recent update. J. Org. Chem. 2017, 82, 11981-11989. [CrossRef]

9. L'Abbé, G.; Godts, F. Synthesis and thermal decomposition of 4-azidoisoxazoles. Bull. Soc. Chim. Belg. 1987, 96, 229-236. [CrossRef]

10. Anderson, D.J.; Muchmore, C.R. Rearrangements of 5-azidoisoxazoles. J. Heterocycl. Chem. 1995, 32, 1189-1196. [CrossRef]

11. Kumar, G.; Rajagopalan, K.; Swaminathan, S.; Balasubramanian, K.K. An interesting fragmentation during the thermolysis of azido isoxazoles. Tetrahedron Lett. 1979, 20, 4685-4686. [CrossRef]

12. L'Abbé, G.; Dyall, L.; Meersman, K.; Dehaen, W. Rates and products from thermolysis of 5-azidoisoxazoles in solution. J. Chem. Soc. Perkin Trans. 2 1996, 2111-2118. [CrossRef]

13. Foresman, J.B.; Frisch, Æ. Exploring Chemistry with Electronic Structure Methods; Gaussian, Inc.: Pittsburgh, PA, USA, 1996.

14. Lee, C.; Yang, W.; Parr, R.G. Development of the Colle-Salvetti correlation-energy formula into a functional of the electron density. Phys. Rev. B 1988, 37, 785-789. [CrossRef] [PubMed]

15. Tomasi, J.; Mennucci, B.; Cancès, E. The IEF version of the PCM solvation method: An overview of a new method addressed to study molecular solutes at the QM ab initio level. J. Mol. Struct.: THEOCHEM 1999, 464, 211-226. [CrossRef]

16. Marenich, A.V.; Cramer, C.J.; Truhlar, D.G. Universal solvation model based on solute electron density and on a continuum model of the solvent defined by the bulk dielectric constant and atomic surface tensions. J. Phys. Chem. B 2009, 113, 6378-6396. [CrossRef]

17. Foresman, J.B.; Keith, T.A.; Wiberg, K.B.; Snoonian, J.; Frisch, M.J. Solvent effects. 5. Influence of cavity shape, truncation of electrostatics, and electron correlation on ab initio reaction field calculations. J. Phys. Chem. 1996, 100, 16098-16104. [CrossRef] 
18. Takano, Y.; Houk, K.N. Benchmarking the conductor-like polarizable continuum model (CPCM) for aqueous solvation free energies of neutral and ionic organic molecules. J. Chem. Theory Comput. 2005, 1, 70-77. [CrossRef]

19. Cramer, C.J.; Truhlar, D.G. Implicit solvation models: Equilibria, structure, spectra, and dynamics. Chem. Rev. 1999, 99, 2161-2200. [CrossRef]

20. Tirado-Rives, J.; Jorgensen, W.L. Performance of B3LYP density functional methods for a large set of organic molecules. J. Chem. Theory Comput. 2008, 4, 297-306. [CrossRef]

21. Kruse, H.; Goerigk, L.; Grimme, S. Why the standard B3LYP/6-31G* model chemistry should not be used in DFT calculations of molecular thermochemistry: Understanding and correcting the problem. J. Org. Chem. 2012, 77, 10824-10834. [CrossRef]

22. Yanai, T.; Tew, D.P.; Handy, N.C. A new hybrid exchange-correlation functional using the Coulomb-attenuating method (CAM-B3LYP). Chem. Phys. Lett. 2004, 393, 51-57. [CrossRef]

23. Zhao, Y.; Truhlar, D.G. The M06 suite of density functionals for main group thermochemistry, thermochemical kinetics, noncovalent interactions, excited states, and transition elements: Two new functionals and systematic testing of four M06-class functionals and 12 other functionals. Theor. Chem. Acc. 2008, 120, 215-241.

24. Becke, A.D. Density-functional thermochemistry. III. The role of exact exchange. J. Chem. Phys. 1993, 98, 5648-5652. [CrossRef]

25. Frisch, M.J.; Trucks, G.W.; Schlegel, H.B.; Scuseria, G.E.; Robb, M.A.; Cheeseman, J.R.; Scalmani, G.; Barone, V.; Petersson, G.A.; Nakatsuji, H.; et al. Gaussian 16, Revision, C.01; Gaussian, Inc.: Wallingford, CT, USA, 2016.

26. Travers, M.J.; Cowles, D.C.; Clifford, E.P.; Ellison, G.B. Photoelectron spectroscopy of the phenylnitrene anion. J. Am. Chem. Soc. 1992, 114, 8699-8701. [CrossRef]

27. Wijeratne, N.R.; Da Fonte, M.; Ronemus, A.; Wyss, P.J.; Tahmassebi, D.; Wenthold, P.G. Photoelectron spectroscopy of chloro-substituted phenylnitrene anions. J. Phys. Chem. A 2009, 113, 9467-9473. [CrossRef]

28. Hayes, J.C.; Sheridan, R.S. The IR spectrum of triplet phenylnitrene. On the origin of didehydroazepine in low temperature matrices. J. Am. Chem. Soc. 1990, 112, 5879-5881. [CrossRef]

29. Leyva, E.; Platz, M.S.; Persy, G.; Wirz, J. Photochemistry of phenyl azide: The role of singlet and triplet phenylnitrene as transient intermediates. J. Am. Chem. Soc. 1986, 108, 3783-3790. [CrossRef]

30. Wenthold, P.G. Spin-state dependent radical stabilization in nitrenes: The unusually small singlet-triplet splitting in 2-furanylnitrene. J. Org. Chem. 2012, 77, 208-214. [CrossRef]

31. Feng, R.; Lu, Y.; Deng, G.; Xu, J.; Wu, Z.; Li, H.; Liu, Q.; Kadowaki, N.; Abe, M.; Zeng, X. Magnetically bistable nitrenes: Matrix isolation of furoylnitrenes in both singlet and triplet states and triplet 3-furylnitrene. J. Am. Chem. Soc. 2018, 140, 10-13. [CrossRef]

32. Rajam, S.; Jadhav, A.V.; Li, Q.; Sarkar, S.K.; Singh, P.N.D.; Rohr, A.; Pace, T.C.S.; Li, R.; Krause, J.A.; Bohne, C.; et al. Triplet sensitized photolysis of a vinyl azide: Direct detection of a triplet vinyl azide and nitrene. J. Org. Chem. 2014, 79, 9325-9334. [CrossRef]

33. Zhang, X.; Sarkar, S.K.; Weragoda, G.K.; Rajam, S.; Ault, B.S.; Gudmundsdottir, A.D. Comparison of the photochemistry of 3-methyl-2-phenyl-2H-azirine and 2-methyl-3-phenyl-2H-azirine. J. Org. Chem. 2014, 79, 653-663. [CrossRef]

34. Lopes, S.; Nunes, C.M.; Gómez-Zavaglia, A.; Pinho e Melo, T.M.V.D.; Fausto, R. Structure and photochemical behavior of 3-azido-acrylophenones: A matrix isolation infrared spectroscopy study. Tetrahedron 2011, 67, 7794-7804. [CrossRef]

35. Gamage, D.W.; Li, Q.; Ranaweera, R.A.A.U.; Sarkar, S.K.; Weragoda, G.K.; Carr, P.L.; Gudmundsdottir, A.D. Vinylnitrene formation from 3,5-diphenyl-isoxazole and 3-benzoyl-2-phenylazirine. J. Org. Chem. 2013, 78, 11349-11356. [CrossRef] [PubMed]

36. Gatlin, D.M.; Karney, W.L.; Abe, M.; Ault, B.S.; Gudmundsdottir, A.D. Formation and reactivity of triplet vinylnitrenes as a function of ring size. J. Org. Chem. 2019, 84, 9215-9225. [CrossRef] [PubMed]

37. Sarkar, S.K.; Osisioma, O.; Karney, W.L.; Abe, M.; Gudmundsdottir, A.D. Using molecular architecture to control the reactivity of a triplet vinylnitrene. J. Am. Chem. Soc. 2016, 138, 14905-14914. [CrossRef]

38. Sarkar, S.K.; Sawai, A.; Kanahara, K.; Wentrup, C.; Abe, M.; Gudmundsdottir, A.D. Direct detection of a triplet vinylnitrene, 1,4-naphthoquinone-2-ylnitrene, in solution and cryogenic matrices. J. Am. Chem. Soc. 2015, 137, 4207-4214. [CrossRef]

39. Osisioma, O.; Chakraborty, M.; Ault, B.S.; Gudmundsdottir, A.D. Wavelength-dependent photochemistry of 2-azidovinylbenzene and 2-phenyl-2H-azirine. J. Mol. Struct. 2018, 1174, 94-101. [CrossRef] 
40. Ault, B.S. Infrared spectra of argon matrix-isolated alkali halide salt/water complexes. J. Am. Chem. Soc. 1978, 100, 2426-2433. [CrossRef]

41. Stratmann, R.E.; Scuseria, G.E.; Frisch, M.J. An efficient implementation of time-dependent density-functional theory for the calculation of excitation energies of large molecules. J. Chem. Phys. 1998, 109, 8218-8224. [CrossRef]

42. Bauernschmitt, R.; Ahlrichs, R. Treatment of electronic excitations within the adiabatic approximation of time dependent density functional theory. Chem. Phys. Lett. 1996, 256, 454-464. [CrossRef]

43. Foresman, J.B.; Head-Gordon, M.; Pople, J.A.; Frisch, M.J. Toward a systematic molecular orbital theory for excited states. J. Phys. Chem. 1992, 96, 135-149. [CrossRef]

44. Gonzalez, C.; Schlegel, H.B. An improved algorithm for reaction path following. J. Chem. Phys. 1989, 90, 2154-2161. [CrossRef]

45. Gonzalez, C.; Schlegel, H.B. Reaction path following in mass-weighted internal coordinates. J. Phys. Chem. 1990, 94, 5523-5527. [CrossRef]

46. Aquilante, F.; Autschbach, J.; Carlson, R.K.; Chibotaru, L.F.; Delcey, M.G.; De Vico, L.; Fernández Galván, I.; Ferré, N.; Frutos, L.M.; Gagliardi, L.; et al. MOLCAS 8: New capabilities for multiconfigurational quantum chemical calculations across the periodic table. J. Comput. Chem. 2016, 37, 506-541. [CrossRef] [PubMed]

47. Schaftenaar, G.; Noordik, J.H. Molden: A pre- and post-processing program for molecular and electronic structures. J. Comput. Aided Mol. Des. 2000, 14, 123-134. [CrossRef] [PubMed]

Sample Availability: Samples of azidoisoxazole $\mathbf{1}$ is available from the authors.

(C) 2020 by the authors. Licensee MDPI, Basel, Switzerland. This article is an open access article distributed under the terms and conditions of the Creative Commons Attribution (CC BY) license (http://creativecommons.org/licenses/by/4.0/). 